\title{
Approaches to therapy and prevention of frailty in the light of contemporary medicine
}

\author{
MARIA MAGDALENA BUJNOWSKA-FEDAK ${ }^{1, \mathrm{~A}, \mathrm{~B}, \mathrm{D}-\mathrm{F}}$, JOANNA WALIGÓRA ${ }^{1, \mathrm{~B}, \mathrm{D}-\mathrm{F}}$, \\ BARBARA D'AVANZO², D, F, CAROL HOLLAND, D, F, DONATA KURPAS ${ }^{1, D, F}$ \\ ${ }^{1}$ Department of Family Medicine, Wroclaw Medical University, Poland \\ ${ }^{2}$ Laboratory of Quality Assessment of Geriatric Therapies and Services, IRCCS - Istituto di Ricerche Farmacologiche \\ Mario Negri, Milan, Italy \\ ${ }^{3}$ Aston Research Centre for Healthy Ageing, School of Life and Health Sciences, Aston University, Birmingham, \\ United Kingdom
}

A - Study Design, B - Data Collection, C - Statistical Analysis, D - Data Interpretation, E - Manuscript Preparation, F - Literature Search, G - Funds Collection

Summary Over the last several decades, the growing number of patients with geriatric problems has become a serious challenge for primary care physicians. Frailty is an often encountered condition in older age. This is a state of increased vulnerability and loss of total physiological reserves, needed to maintain physiological and psychosocial homeostasis. Definition of physical frailty is based on the following criteria: unintentional weight loss, self-reported exhaustion, weakness, slow walking speed, and low physical activity, where 3 out of 5 these criteria confirms frailty. It is a dynamic, transitional process which constantly progresses, although it is potentially reversible. Frailty often co-exists with other severe diseases, affecting general well-being of the patient. Therefore, it is important for the family doctor to understand diagnosis and treatment to protect from an invasive procedure or potentially harmful medication, and prevent decline of functional independence. The aim of this review is to present current available treatment options and their effectiveness for frailty. Data from many observational studies were collected. The most beneficial seems to be combined multidisciplinary treatment including physical exercises, nutritional supplementation and cognitive training. Additionally, the further positive results of physical activity training on mobility, balance, coordination, muscle strength and reducing falls in frail elderly were also confirmed by many scientific reports. Pharmacological, nutritional, psychological and other interventions solely can also be helpful but the evidence is low. Preventive actions at many stages in the process leading to frailty can be applied. Key words: therapy, prevention, aging, frailty, intervention.

Bujnowska-Fedak MM, Waligóra J, D'Avanzo B, Holland C, Kurpas D. Approaches to therapy and prevention of frailty in the light of contemporary medicine. Fam Med Prim Care Rev 2017; 19(3): 289-297, doi: https://doi.org/10.5114/fmpcr.2017.69293.

\section{Background}

It is common knowledge that the ageing population and healthcare systems are facing new challenges related to multimorbidity and polypharmacy. One of the most relevant, problems of older age is the frailty syndrome, which is becoming more frequently diagnosed. It is a state of increased vulnerability, where multiple systems are involved. It correlates with the loss of total physiological reserves, as well as impaired ability to withstand intrinsic and environmental stressors and maintain physiological and psychosocial homeostasis [1-4].

Several studies have proven that a considerable number of older patients who visit primary care physicians experience this condition. The prevalence of frailty varies widely according to different phenotypes and the population under study. One of the latest systematic literature reviews showed an enormous spread of frailty prevalence in community-dwelling adults aged 65 and older - a range of 4.0-59.1\%. The prevalence regarding the physical phenotype of frailty was about $9.9 \%$ and for the broader phenotype of frailty - $13.6 \%$ [5]. A subsequent survey of 7510 community-dwelling elders carried out within European countries revealed that the prevalence of frailty varied from $5.8-27 \%$, the highest in Switzerland, the lowest in Spain, with an average prevalence of $17 \%$ [3]. In Poland, based on the studies by Uchmanowicz et al., even $40 \%$ of people aged $64-71$ are at risk of frailty [6]. Frailty is a leading cause of death in older people, as demonstrated in a ten-year prospective cohort study involving community dwelling older people, which revealed frailty as a cause of death of $27,9 \%$ surveyed, compared to organ failure $(21,4 \%)$, cancer $(19,3 \%)$, dementia $(13,8 \%)$ and other causes $(14,9 \%)$ [4]. Based on Ommundsen et al. data [7], in frail and non-frail patients 1-year survival was $80 \%$ and $92 \%$, respectively. With the extension of the study time, the difference in mortality between non-frail and frail increased. In a study among frail patients at over 65 years of age, 5-year survival was $24 \%$, but in non-frail patients, 5 -year survival was $66 \%$. Shamliyan et al. [8] estimated that $3-5 \%$ of deaths among older adults could be delayed if frailty was prevented.

As far as the risk factors of frailty are concerned, although frailty syndrome development is possible in young people, e.g. intensive care unit (ICU) patients, the association with age is clear [9]. It occurs more often in older women than men and in African Americans than in White Europeans. There is scientific evidence of genetic influences on frailty, although the highest contribution is due to environmental factors [3, 9-11]. Particularly, low socio-economic status and the related malnutrition have a huge influence on the development of the frailty syndrome. Malnutrition plays an essential part in the pathogenesis of frailty and sarcopenia [12]. It leads to age-related muscle loss as well as a simple decrease in physical activity. Low 25-hydroxyvitamin $\mathrm{D}[25(\mathrm{OH}) \mathrm{D}]$ levels are common in older adults $[13,14]$ and have been linked to falls $[15,16]$, fractures [15], 
pain $[13,15]$, sarcopenia [14], disability [13], and frailty [17, 18]. Furthermore, according to Lang et al., [19] frailty and co-morbidity often co-exists - as is the case within $46.2 \%$ of the population, whereas frailty and disability was present in $5.7 \%$, and the combination of frailty, disability and co-morbidity was present in $21.5 \%$ of the study group. However, frailty, without co-morbidity or disability occurred within $26.6 \%$ of the study group [19].

The presence of a variety of scales to measure frailty is the result of uncertainty about the term itself as well as its components [20]. Despite the number of definitions of the frailty syndrome presented in a large body of scientific literature, none of it constitutes a gold standard. Moreover, it has not yet been ICD-10 classified. The first definitions of the 'frail elderly' included: those over 75 , physically or mentally handicapped seniors, older patients under a geriatric program or requiring institutional treatment, and seniors unable to cope by themselves in activities of daily living (ADLs) [10]. The most commonly used definition now is that developed by Fried et al., based on five phenotypic criteria: unintentional weight loss, self-reported exhaustion, weakness (low grip strength), slow walking speed, and low physical activity [3, 21,22]. Fulfilling 3 out of 5 of these criteria confirms frailty, 1 or 2 - pre-frailty. Whereas Rockwood et al. [20] presented a slightly different approach to describe the frailty syndrome. They have created a frailty index (FI), which is a proportion of the number of deficits which the patient is presenting out of the total number of deficits distinctive for frailty. The higher the score, the more frail the individual. Rockwood's study consists of 70 of those features [20]; the deficits include diseases, signs, symptoms, laboratory abnormalities, cognitive impairments, and disabilities in activities of daily living.

It should be stressed that frailty is a dynamic, transitional process which constantly progresses. It is potentially reversible unless it caused disability [19]. The frailty process is extended in time and the three stages of it can be described as: a pre-frail stage (where one or two of above mentioned criteria are present, and possibly with the risk of progression), the frailty state and finally - frailty complications $[3,19,22]$. The pre-frail stage may be clinically silent. At this time total physiological reserves are beginning to run out, but they are still sufficient to deal with stressors, pathogens and injuries and there is a chance of speedy recovery. Whereas during frailty, if appropriate care is not provided, impairment of the systems does not allow for a complete return to the normal state of health. It is bound to result in poor health outcomes, including falls, disability, hospitalization and ultimately leading to death $[3,19]$.

This paper focuses on the current state of knowledge regarding the treatment of frailty and the possible preventative approaches. It is worth emphasizing that frailty itself can be recognized clinically and measured relatively easily, and therefore may be a useful gauge for improving the health of older people. This would help in planning interventions, implementing treatment or determining if hospitalization or institutional care is necessary. Early recognition and prompt interventions should be the major issues for general practice.

\section{Interventions}

Uniform guidelines for the management of frailty have not yet been developed, although the approaches under investigations are in clinical trial phases at the moment.

\section{Physical activity}

Suppressing disability and maintenance of independent function should be the primary goal of any physician who takes care of older patients. Several systematic reviews have come to the same conclusion that exercise is a key to improve physical capacity and general health in older adults with the frailty syndrome [23-26]. Physical exercises are very beneficial for the mobility of older people; they improve balance and coordination, increase walking speed, muscle strength and movement range, reduce falls, increase bone mineral density, relieve arthralgia, relax mood, positively impact depression, and promote cognitive health [27-31]. Attention should be paid, in particular, to the need for a person with the frailty syndrome to perform basic activities of daily living (ADL), such as dressing, bathing, personal hygiene and grooming, toilet hygiene, self-feeding and functional mobility [32]. The HOPE trial was designed for older people with frailty to improve mobility and function [33]. The core constituents of this program were strengthening exercises for the muscle groups required for basic mobility skills. This is highly accessible training because it does not require any special equipment and can be performed without professional supervision [33]. The next step should be to improve the instrumental activities of daily living (IADL) such as phone use, shopping, cooking, etc. that enable people to participate in day to day family, social, and sometimes even professional life. Beneficial effect on IADL was evaluated in the study by Gitlin et al. [34]. This intervention was based on home visits during which occupational therapists provided education and physical and social environmental modifications which resulted in improvement in self-efficacy of the patients after 3 months of the intervention [34].

Physical activity is advisable for all seniors regardless of their advancement in years, illnesses and general health condition [29]. It is reported by Toulotte et al. that physical exercises have positive effects even among very elderly patients with frailty [35]. The study was undertaken on 20 older $(81,4 \pm 4,7$ years old) patients with dementia, with a history of falls. After 16 weeks of training, a significant improvement of walking, flexibility and static balance was observed. Physical training can also be associated with improved mobility of patients and their spontaneous physical activity, which is a particularly important result, because the residents often experience decline in physical activity after entry to a care home [36]. On the other hand, after hospitalization, frail older people do not recover completely and are at increased risk of further functional deterioration [37]. An out-patient multicomponent training program was evaluated in a 10-week intervention period with a 3-and 9-months follow-up conducted by Timonen et al. [37]. After intervention, significant improvements in strength, balance, walking speed and mobility were observed [37]. However those who were most frail appeared to gain least benefit [38].

Exercise was once considered dangerous for frail adults with concerns that it may expose them to injuries. However, physical activity is now established as very beneficial and safe, decreasing risk of falls [26]. Various types of exercise can be performed, for example, aerobic, resistance, endurance, balance, flexibility, task-oriented, goal-setting and tai-chi exercises [39]. Studies show that the most beneficial for frail patients are those involving strength and balance training [40]. Tai-chi is also recommended for older people because it does not require much physical effort and is easy to do. It engages the whole body, improves coordination, balance, posture, reduces the risk of falls, increases muscle strength and elasticity [23, 41]. Tai-chi directly or indirectly affects three basic components of frailty: weakness, slow gait and low physical activity. In Wolf's study, the 48-week program of tai-chi significantly reduced the fear of falling and reduced, without statistical significance, the number of falls [42].

In clinical studies, different effects of exercise on frailty have been demonstrated. A 12-week multicomponent exercise program composed of resistance training with balance and gait retraining exercises, provided to institutionalized patients, improved Timed Up-and-Go test performance with single and dual tasks, as well as rise from a chair and balance [43]. This multicomponent exercise program also enhanced high-density muscle cross-sectional area, reduced incidence of falls and postponed deterioration in ADLs [43]. 
Difference according to exercise frequency has been shown. For example, in a water exercise intervention - twice-weekly exercise showed more rapid improvement than once-weekly [44]. Another study, a 3-month intervention with 6 months follow-up provided at the residential care home, showed that an exercise program may improve health status even in a relatively short term [36], although the other long-term, 2-year study showed that the training programs should be continued as long as possible to keep frail patients active and to gain the most benefits in strength and functional performance [45].

Physical exercise programs delivered in class or groups proved to be more effective compared to those performed individually [46]. Home-based exercise programs improved only mobility [33]; computerized balance training which was performed individually under the supervision of instructors did not show any effects [47]. However, recent findings suggest that when a home exercise program is comprehensive and carefully implemented, it can also result in many benefits [46]. Further study is required to establish sustainability of positive outcomes.

There should be more emphasis put on promotion and implementation of physical activity interventions in frail patients. Family physicians have the greatest overall impact encouraging their patients to get healthy habits and become active [26, 28]. Patients should be educated about how safe and easy is to do physical training. It is never too late to start exercise, in fact those who go from none to some exercises receive the greatest health benefits $[27,28]$.

\section{Pharmaceuticals}

The purpose of treatment is to reduce potentially modifiable risk factors of frailty. One of them is vitamin $D$ deficiency. Vitamin $D$ deficiency is very common among older people over 65 years old. Levels of 25(OH)D above $30 \mathrm{ng} / \mathrm{mL}$ are considered normal; levels below $12 \mathrm{ng} / \mathrm{mL}$ are diagnosed as 25(OH)D deficiency and levels between 12 and $30 \mathrm{ng} / \mathrm{mL}$ indicate $25(\mathrm{OH}) \mathrm{D}$ insufficiency [48]. Numerous studies have reported that about $90 \%$ of senior citizens (65 years and above) have low vitamin $D$ levels, even those living in the areas of the world with high exposure to sunlight [49]. Constant vitamin D supplementation in combination with calcium improves the balance and coordination of older people, it diminishes the number of falls and reduces the risk of fractures $[31,40]$. According to Morley et al. [50] the supplementation of vitamin D significantly contributes to improved functional efficiency, increases muscle strength, lowers falls, as well as mortality in patients with sarcopenia. Therefore all sarcopenic patients should have their 25(OH)D levels measured [49]. Meta-analysis demonstrated effects on muscle strength in older patients taking vitamin $D$ [51], although the effects are small to moderate. Pfeifer et al. [52] conducted a 6- month treatment, taking $800 \mathrm{IU} /$ day vitamin $D_{3}$ orally and they found significantly increased quadriceps strength. Similarly, Moreira-Pfrimer et al. [53], after treatment of people over 60 years old by a 6 -month supplementation of daily calcium plus oral vitamin $D_{3}(150000 \mathrm{IU}$ once a month during the first 2 months, followed by $90000 \mathrm{IU}$ once a month for the last 4 months) found significantly improved maximal isometric strength of hip flexors and knee extensors compared with placebo. Effects of vitamin $D$ treatment have been evaluated in a Japanese study which included women with post-stroke hemiplegia, who after 2 years of treatment with $1000 \mathrm{IU} /$ day vitamin $D_{2}$ significantly improved strength of the gluteus maximus and iliopsoas muscles on the intact side [54]. On the other hand effects of vitamin $D$ treatment (an average daily dose 400-1200 IU) haven't shown a beneficial effect on hand grip strength [55-58]. Among seven trials testing gait speed [55-61], only Bunout and colleagues [56] found an increased 12-minute gait speed in response to 9 months of treatment with a daily dose of $400 \mathrm{IU}$ vitamin $\mathrm{D}_{3}+800 \mathrm{mg}$ calcium compared with 800 mg calcium alone. There was a statistically significant reduction in the frequency of hip and non vertebral fractures for patients receiving 700 to $800 \mathrm{IU} /$ day oral vitamin D supplementation [15]. However there was no reduction in the frequency of hip or non vertebral fractures for patients receiving $400 \mathrm{IU} /$ day oral vitamin $D$ supplementation. A subsequent study showed that a single intramuscular injection of ergocalciferol (600 000 IU) in older patients with low vitamin $D$ levels reduced postural sway (a known risk factor for falls) during walking [62]. Nonetheless there is still no hard evidence to recommend supplementation with vitamin D by frail older patients. Some of the results are encouraging, but its impact has not been unequivocally confirmed, more research needs to be done.

Supplementation of sex hormones and growth hormone potentially increases muscle mass and reduces adiposity, which raises hopes of improving the functional efficiency of frail older people. Treatment with testosterone raises a lot of controversy. In the research carried out by Ferrando et al. [63] older men under a 6 month long testosterone treatment increased their total and leg lean body mass, muscle volume, and leg and arm muscle strength but also they developed some severe complications such as: aggressive behavior, thrombosis, edema, gynaecomastia, prostate cancer, lipid disorders and other $[29,63$, 64]. As regards to dehydroepiandrosterone (DHEA), Muller et al.'s intervention [65] did not demonstrate significant effects of DHEA, atamestane, or a combination on physical frailty, muscle strength, and functional performance, and no effects of these interventions were observed on bone mineral density (BMD), body composition, general well-being, cognitive function, and atherosclerosis. Another study, provided by Morales et al. [66], on a group of men in the 50-65 age bracket who were taking $100 \mathrm{mg}$ DHEA for 6 months, showed a significant $6,1 \%$ increase in knee muscle strength, and a $13,6 \%$ increase in lumbar back strength, without increasing the overall muscle mass. On the other hand, a group of women who were taking the same dose gained on average 1,4 kg weight without increasing muscle strength. No side effects of using DHEA raises hope for treating frailty, but the lack of unequivocally documented benefits limits its use in older people as yet.

In older age, growth hormone secretion is significantly reduced [2]. Growth hormone stimulates the liver to produce insulin-like growth factor 1 (IGF-1) which directly affects the receptors on skeletal muscles. Therefore it might be beneficial to supplement growth hormone in frail patients with lower muscle mass. Rudman et al. [67] conducted a six month prospective trial of growth hormone replacement in men aged $61-80$ years who had decreased IGF-1 levels. As a result a 3,7 kg increase in non-fat mass, without improving of muscle strength and loss of $2,4 \mathrm{~kg}$ fat mass was observed. Just one randomized, controlled trial that combined both growth hormone and sex steroid showed small but statistically significant gain in total body strength, but in male participants only [68]. Additionally the use of growth hormone is associated with significant adverse effects such us: insulin resistance, gynaecomastia, fluid retention, arthralgia and carpal tunnel syndrome $[68,69]$. Current results of scientific research on this issue are inconsistent, therefore hormone therapy is not officially recommended for the treatment of older patients with frailty.

Another considerable option of treatment could be the use of angiotensin converting enzyme inhibitors (ACEI) [2]. It is not surprising that they have a positive effect on skeletal muscles. In an observational study of older women with hypertension taking ACEI, a lower mean decline in muscle function was observed, compared to a group taking other drugs [70]. A double-blind randomized trial of 130 patients over 65 years old experiencing decreased mobility or functional impairment, under 20-week course of perindopril, showed improved physical capacity [71]. The biggest improvement was observed in younger group of patients (in the 65-80 age bracket) [71]. The results are promising although further research is required. 


\section{Nutrition}

Nutrition plays a fundamental role in the design of intervention strategies aimed at re-establishing robustness [72].

The European Society of Parenteral and Enteral Nutrition (ESPEN) recommends, with evidence level $A$, the use of nutritional supplements to improve or maintain the health status of frail elderly people [73]. Providing not only nutritional supplements alone, but also including milk fat globule membrane (MFGM) [74], protein - energy formula [75], increasing protein - calorie and micronutrients intake [76] was proven to be beneficial for patients with frailty syndrome. Nonetheless, the evidence of uniquely effective nutrition intervention in the studies is inconsistent.

There is an increase of muscle catabolism in frailty. Research clearly shows that enlargement in protein intake in diet increases muscle anabolism and makes other positive contributions to good health, e.g. reduces the progression of functional decline and helps in recovery from illness [48]. Currently recommended dose of the daily protein intake (Recommended Dietary Allowance, RDA) of $0,8 \mathrm{~g} / \mathrm{kg}$ turned out to be insufficient for the maintenance of muscle mass [77]. Although in two other studies the administration of $1,5 \mathrm{~g} / \mathrm{kg} /$ day of protein, with a balanced spread throughout the three main meals, combined with high doses of calcium (100-1200 mg/day) and vitamin D (more than $800 \mathrm{IU} /$ day) showed an improvement in bone and muscle health and reduced the risk of falls and fractures $[78,79]$.

According to the clinical trial by Bauer et al. [80] nutritional supplementation could positively influence aspects of sarcopenia and thus prevent physical disability. In their research, frail patients were taking the product, which contained, per serving, $20 \mathrm{~g}$ whey protein, $3 \mathrm{~g}$ total leucine, $9 \mathrm{~g}$ carbohydrates, $3 \mathrm{~g}$ fat, $800 \mathrm{IU}$ vitamin $\mathrm{D}$ and a mixture of vitamins, minerals and fibers. After intervention of 13-week duration an improvement in chair-stand time, appendicular muscle mass, quality of life (as measured using EQ-5D VAS score) was observed. However there was no significant difference in handgrip strength [80]. As the research show, the specific nutritional supplementation alone is clearly beneficial for frail patients, and is especially recommended for those who are unable to exercise [80]. On the other hand, Smoliner et al. [81] did not show any beneficial effect of nutrition in their study. They examined a group of aged residents of care homes who were at risk of malnutrition, and found no significant difference between the nutritional intervention group, who had an intake of a higher amount of protein, and the control group, either in their Mini Nutritional Assessment (MNA) scores or in their Body Mass Index (BMI) at the end of the study. Subsequent intervention, examining a group of 100 frail very elderly people (the mean age was 87,1 ) reported that nutritional supplementation had no effect on muscle strength, gait speed, stair climbing or physical activity [35]. The intervention of fatty acid supplementation ( $\alpha$-linolenic acid) while completing a resistance training program ( 3 days a week) for 12 weeks, showed no effect of the supplementation on muscle mass or muscle strength as well [82].

Very limited evidence showed the beneficial effects of the essential amino acids (EAA) supplementation, especially leucine, on muscle mass and function $[83,84]$. $\beta$-hydroxy $\beta$-methylbutyric acid (HMB; a bioactive metabolite of leucine) supplementation with arginine [85] or alone [85-88] seems to have some effects on muscle mass and muscle function but sample sizes in these trials were small. No effect of protein-energy supplementation on physical capacities was shown in four further studies [89-92]. In one study only physical performance was improved, but not muscle mass or muscle strength [93]. However protein-energy supplementation could be beneficial if administered to undernourished older adults [75].

Summarizing, the large majority of the studies have demonstrated too little evidence to recommend nutritional supplementation in the treatment of frailty. But older people over 65 years old, bedridden or home dependent, frequently having multimorbidity, with reduced functional and intellectual capability, are at great risk for malnutrition which is also a component of frailty. For this reason malnutrition comes up as a frequently encountered health situation for a frail older population. Since 2002, all of the published ESPEN (European Society of Clinical Nutrition and Metabolism) guidelines recommend screening the nutritional status of all individuals over 65 years old, routinely. Screening of nutritional status is considered to be a simple process which aims to identify those malnourished or at significant risk of malnourishment. In case of detected risk of malnutrition either supplementation or supporting dietary recommendations alone will be offered to the patients [73].

\section{Combined multidisciplinary treatment}

Many studies demonstrate that the most beneficial interventions for frail elders are combined multidisciplinary treatment. An intervention including physical training $(90$ minutes 2 times a week), nutritional supplementation (increasing protein-calorie and micronutrients intake every day), and cognitive training ( 2 hours per week, designed to stimulate short-term memory, and enhance attention, information-processing skills, and reasoning and problem-solving abilities), proved to have significant impact on frailty components at 3- 6- and 12-month follow up, especially in improving leg strength, gait speed and increasing physical activity, based on data gathered by $\mathrm{Ng}$ et al. [76]. Studies show that diet and exercise is more effective than diet or exercise alone in improving frailty indicators [94]. The most effective strategy to increase muscle mass, strength and physical ability is to regularly exercise and take protein supplementation after exercise [48]. A subsequent 12-month multifactorial intervention by Fairhall et al. [95] significantly improved mobility, strength and balance measures. They focused mostly on physical exercise but also on medical management. An interdisciplinary team included two physiotherapists, a geriatrician, rehabilitation physician, dietician and nurse, who were meeting regularly in case conferences and case management. A home program was implemented to enhance safety in the home environment, recommend mobility aids and to provide safety advice. As a result the majority of the study group achieved transition out of frailty.

Moreover Luger et al. [96] performed an investigation with patients aged 65 years and older who still lived in their own houses - they were visited twice a week by trained nonprofessional volunteers to support exercises and nutrition-related aspects. As a result an improvement of daily physical activity, physical performance, balance skills and general well-being (according to a Quality of Life scale) was shown. This home-based physical training, nutritional, and social support intervention turned out to be feasible and helpful to tackle malnutrition and frailty in older people living at home. Additionally, $10 \%$ reduction in fear of falls (FOF) was observed (as measured using the Falls Efficacy Scale-International) [97]. Furthermore, the social support program proved to be effective regardless of other forms of intervention, significantly reducing the sense of loneliness and environmental isolation of seniors [98]. It should be emphasized that 'social participation' is a key factor for the well-being and mental health of older persons [98].

\section{Other interventions}

Taking into account the complex approach to frailty we should also consider psychological interventions. A 3-month problem-solving intervention [99] was shown to have no effects on primary outcomes of frailty. However, other therapies may be more pertinent. Depression often goes undetected and untreated in frail elderly patients [100]. Findings show that the more frail an older person is, the more likely it is that he or she will become depressed [100], and this is an important factor 
that should not be ignored. Significantly, recent studies highlight that compliance in treatment of older people is an important indicator of therapeutic effectiveness [101], and depression may have a significant role in non-adherence and so negatively influence the treatment for significant co-morbidities.

Psychological interventions can improve the functional health of depressed older patients although investigations have shown moderate effects [100]. Therapy aimed at the production of a positive psychological state have been suggested to strengthen other interventions e.g. physical, nutritional and pharmacological [102]. In the wider health psychology literature, the role of self-efficacy, and pre-intervention self-affirmation to support self-efficacy, is evidenced as important in improving adherence to new healthy lifestyle behavior changes, supporting its potential use in frailty interventions [103].

Another psychological intervention, cognitive behavioral therapy (CBT) has been shown to demonstrate impacts on frailty related symptoms such as fear of falling [104]. In the study standard cognitive-behavioral clinical assessment interviews were used to elicit the factors of participants' problems, causing their anxiety or depression [104]. However, perhaps most salient in the literature on psychological interventions, more and more research shows that cognitive training targeting attention and executive function improves motor balance and gait speed [76, 105-108].

Multi-professional senior meetings, administered 4 times, were found to be more effective in maintaining of independency in ADLs than a single preventive home visit conducted by a specially trained professional. During meetings led by collaborative multi-professional intervention team (physiotherapists, nurse and a qualified social worker), participants received an information about possible health consequences of the aging process and were provided with strategies for solving the various problems [109]. Moreover, both individual and group educational sessions with a geriatrician showed the significant positive effect on the participants at risk of depression in the course of frailty syndrome [110].

Furthermore proactive home visits by trained community nurses were conducted which were focused mainly on education for patients with frailty syndrome in terms of proper nutrition, management of medications, physical activity, sleep hygiene, and other health related areas [111, 112]. As a result only slight positive effects on components of the frailty were shown. They were observed only in the group where the patients were able to contact their nurses whenever they felt the need by pressing an alert button. Unsatisfactory results of the intervention might be caused by three possible reasons. First, linkage with primary care physicians was limited. Second, home visits were not offered to a part (16\%) of the intervention group. Third, the frequency of home visits (4 per year) might not be sufficient. The search for effectiveness of nurse home visits requires further investigation, which might also take into account the point of view of frail older people as it emerges from qualitative research $[113,114]$.

\section{Prevention}

Preventive actions at many stages in the process leading to frailty can be applied. Properly implemented procedures can prevent this process at its beginning as well as at further stages once frailty has developed, although some evidence suggests that intervention in participants with severe frailty might not be as beneficial as in the early stages of this process [24].

Attention should be paid to the treatment of co-morbid conditions and associated polypharmacy [115]. Distinct mechanisms of chronic diseases can cause frailty. Screening for osteoporosis, cancer, malnutrition and cardiovascular diseases should be undertaken for adults aged 65 and over [116]. The number and type of medicines needed to treat, their side-effects and interactions should be monitored, because they can contribute to frailty [25]. Frailty is a complex dynamic process and it is particularly important to properly identify therapeutic targets, because compensatory mechanisms and primary dysfunctions caused by disease can coincide [25]

Research shows that physical activity is an important factor to postpone and prevent frailty [31, 110, 115, 117]. It has an impact on potentially modifiable risk factors of frailty like obesity, high blood pressure, hypercholesterolaemia, insulin resistance etc. [118]. Exercise training is also beneficial in people with mild cognitive impairment which is associated with frailty [117]. It improves cerebral blood flow, increases the activity of several neurotrophic and vascular growth factors, which leads to better neurogenesis, angiogenesis, synaptic plasticity and dendritic spine density in the hippocampus [119].

Due to the fact that infectious diseases are more common with increasing age, often have a more severe course and can lead to complications, routine vaccinations are recommended. Primary care physicians should specifically encourage older patients to receive an annual influenza vaccination $[31,116]$. Likewise vaccinations against pneumococcal, herpes zoster, tetanus vaccination and hepatitis type $B$ are also recommended [31, 116].

Support and family care are significantly important in prevention, demonstrated in several research studies [120, 121]. Patients with high monthly salary and highly functional families, with the strong social support from family members have better physical and mental health, rarely get sick or disabled, and avoid chronic illness complications. High levels of education are also associated with better physical health $[120,121]$. Health education for both frail older patients and their caregivers is essential for the awareness of each preventive intervention. Family physicians need to spend time on health education that will facilitate people's own preventive activities.

Furthermore some studies showed that supplementation of vitamin $D$ is effective in the prevention of frailty $[13,15,17]$. Vitamin D has a multidirectional effect, including bone growth and bone remodeling by osteoblasts and osteoclasts, modulation of cell growth, maintains adequate serum calcium and phosphate concentrations, neuromuscular and immune function, and reduction of inflammation (Dietary Reference Intakes for Calcium and Vitamin D) [122]. The presence of $25(\mathrm{OH}) \mathrm{D}$ receptors is in nearly every tissue. Avitaminosis D causes osteoporosis and osteomalacia in older age, and as a consequence, progressive bone loss, impaired microstructure of bone tissue and, consequently, increased susceptibility to fractures, curvature and degeneration of the skeletal system, and distortion of the body. Several studies showed a beneficial effect of vitamin D in falls and fracture prevention [14-16]. For adequate lower-extremity strength, and falls and fracture prevention, an optimal serum 25-hydroxyvitamin D concentrations should be at least $30 \mathrm{ng} / \mathrm{ml}$ (75 nmol/I) [123]. However, this rationale of vitamin D effect on some biological and clinical indicators, like bone mineral density or fractures, in community dweller older people has been questioned in some studies [124, 125].

\section{Summary}

Caring for frail patients is not easy due to co-morbidity, complexity of medical problems and progressive disability. However, it should be emphasized, that frailty is malleable and manageable and therefore, there may be opportunities along its pathway to manage and/or prevent its negative consequences and decline $[38,76]$. Promoting high quality of life and striving towards autonomy should be an important goal for primary care physicians $[31,126]$. Distinguishing older people who are frail from people who are not frail should therefore form an essential aspect of assessment in any health care encounter that might protect from an invasive procedure or potentially harmful medication, and importantly, lead to recommended interven- 
tions. It allows practitioners to weigh up benefits and risks, and for patients to make properly informed choices.

Summarizing, physical, nutritional, cognitive, and combined interventions are effective in reducing frailty, but there is still a paucity of firm evidence in some areas, and so attempts to optimize effective management are still ongoing. A large body of literature shows that interventions reduce the frequency of morbidity, hospitalization, and admission to residential care facilities. The results of physical activity interventions are generally positive although future studies should be provided with a larger sample size, include a longer follow-up period to determine if the benefits of the treatment are sustained. Anabolic hormones are also effective, but often associated with some severe adverse effects. The evidence does support the benefits of vitamin $\mathrm{D}$ supplements where the patient has a deficit, and possibly the use of angiotensin converting enzyme inhibitors. Nutritional treatment has a low evidence, however it can be provided in malnourished patients who are unable to exercise. Multidisciplinary combined treatment is the most effective and seems to be the best choice for the frail patients. As a result of involvement in choice and care decisions related to receiving the health care and social services, the patient has a greater sense of security, and thus maintains a sense of control over his or her life. Moreover, preventive actions at many stages in the process leading to frailty can be applied. Among different options the most crucial is supplementation of vitamin D which diminishes the number of falls and reduces the risk of fractures. Further study is required to determine how to best embed the intervention into existing health care settings. In doing this, social and psychological factors should be considered, given their role in motivating people to taking part to activities and adhering to treatments. Indeed, qualitative research has shown the importance of the way and the context in which treatments are proposed and offered [127]. Moreover, qualitative studies also showed that prevention and management of frailty cannot be taken as a problem of the isolated individual, rather they should be planned and offered in a community perspective, thus involving the person's full, family, social and environmental context. Contemporary medicine should fully integrate the evidence that even weakly evidence-based interventions for frailty can be effective if they are really person-centred and aimed at the whole older person's well-being. Family physicians have a crucial role in promoting healthy lifestyle and preventing and initiating treatment for frailty. Being the best known and accessible and entering into close relationship with their patients, they have the greatest impact on their desirable health behaviors.

Acknowledgements. The article has been developed as part of a larger program of research 'Frailty Management Optimisation through EIP-AHA Commitments and Utilisation of Stakeholders Input' (FOCUS). The FOCUS project aims to critically reduce and prevent the burden of frailty in Europe by supporting development of the commitments that focus on early diagnosis/screening and on management of frailty, see the website for further information: http://www.focus-aha.eu/web/eu/home and related articles $[126,127]$

Source of funding: The article is part of the project/joint action '664367/FOCUS' which has received funding from the European Union's Health Programme (2014-2020) and Ministry of Science and Higher Education in Poland (funding in years 2015-2018 allocated for the international co-financed project).

Conflict of interest: The authors declare no conflict of interests.

\section{References}

1. Topinkowa E. Aging, disability and frailty. Ann Nutr Metab 2008; 52(Suppl. 1): 6-11.

2. Campbell S, Szoeke C. Pharmacological treatment of frailty in the elderly. J Pharm Pract Res 2009; 39(2): 147-151.

3. Xue QL. The frailty syndrome: definition and natural history. Clin Geriatr Med 2011; 27(1): 1-15.

4. Clegg A, Young J, Iliffe S, et al. Frailty in elderly people. Lancet 2013; 381(9868): 752-762.

5. Collard RM, Boter H, Schoevers RA, et al. Prevalence of frailty in community-dwelling older persons: a systematic review. J Am Geriatr Soc 2012; 60(8): 1487-1492.

6. Uchmanowicz I, Jankowska-Polańska B, Łoboz-Rudnicka M, et al. Cross-cultural adaptation and reliability testing of the Tilburg Frailty Indicator for optimizing care of Polish patients with frailty syndrome. Clin Interv Aging 2014; 9: 997-1001.

7. Ommundsen N, Wyller TB, Nesbakken A, et al. Frailty is an independent predictor of survival in older patients with colorectal cancer. Oncologist 2014; 19(12): 1268-1275.

8. Shamliyan T, Talley KM, Ramakrishnan R, et al. Association of frailty with survival: a systematic literature review. Ageing Res Rev 2013; 12(2): 719-736.

9. Chen X, Mao G, Leng S. Frailty syndrome: an overwiev. Clin Interv Aging 2014; 9: 433-441.

10. Hogan DB, MacKnight C, Bergman H. Steering Committee, Canadian Initiative on Frailty and Aging. Models, definitions, and criteria of frailty. Aging Clin Exp Res 2003; 15(3 Suppl.): 1-29.

11. Viña J, Tarazona-Santabalbina FJ, Pérez-Ros P, et al. Biology of frailty: modulation of ageing genes and its importance to prevent ageassociated loss of function. Mol Aspects Med 2016; 50: 88-108.

12. Cruz-Jenoft AJ, Kiesswetter E, Drey M, et al. Nutrition, frailty, and sarcopenia. Aging Clin Exp Res 2017; 29(1): 43-48

13. Lips P. Vitamin D deficiency and secondary hyperparathyroidism in the elderly: consequences for bone loss and fractures and therapeutic implications. Endocr Rev 2001; 22(4): 477-501.

14. Visser M, Deeg DJ, Lips P. Low vitamin D and high parathyroid hormone levels as determinants of loss of muscle strength and muscle mass (sarcopenia): the Longitudinal Aging Study Amsterdam. J Clin Endocrinol Metab 2003; 88(12): 5766-5772.

15. Bischoff-Ferrari HA, Willett WC, Wong JB, et al. Fracture prevention with vitamin D supplementation: a meta-analysis of randomized controlled trials. JAMA 2005; 293(18): 2257-2264.

16. Snijder MB, van Schoor NM, Pluijm SM, et al. Vitamin D status in relation to one-year risk of recurrent falling in older men and women. J Clin Endocrinol Metab 2006; 91(8): 2980-2985.

17. Shardell M, Hicks GE, Miller RR, et al. Association of low vitamin D levels with the frailty syndrome in men and women. $J$ Gerontol A Biol Sci Med Sci 2009; 64(1): 69-75.

18. Puts MT, Visser M, Twisk JW, et al. Endocrine and inflammatory markers as predictors of frailty. Clin Endocrinol (Oxford) 2005; 63(4): 403-411.

19. Lang PO, Michel JP, Zekry D. Frailty syndrome: a transitional state in dynamic process. Gerontology 2009; 55(5): 539-549.

20. Rockwood K, Song X, MacKnight C, et al. A global clinical measure of fitness and frailty in elderly people. CMAJ 2005; 173(5): 489-495.

21. Fried LP, Tangen CM, Walston J, et al. Cardiovascular Health Study Collaborative Research Group. Frailty in older adults: evidence for a phenotype. J Gerontol A Biol Sci Med Sci 2001; 56(3): M146-M156. 
22. Fried LP, Ferrucci L, Darer J, et al. Untangling the concepts of disability, frailty, and comorbidity: implications for improved targeting and care. J Gerontol A Biol Sci Med Sci 2004; 59(3): 255-263.

23. Cherniack EP, Florez HJ, Troen BR. Emerging therapies to treat frailty syndrome in the elderly. Altern Med Rev 2007; 12(3): 246-258.

24. De Lepeleire J, lliffe S, Mann E, et al. Frailty: an emerging concept for general practice. Br J Gen Pract 2009; 59(562): e177-e182.

25. Weiss CO. Frailty and chronic diseases in older adults. Clin Geriatr Med 2011; 27(1): 39-52.

26. Liu CK, Fielding RA. Exercise as an intervention for frailty. Clin Geriatr Med 2011; 27(1): 101-110.

27. Warner Schaire K, Pietrucha M. Mobility and transportation in the elderly. New York: Springer Publishing Company; 2000.

28. Lobo A. Physical activity and health in the elderly. Emirate of Sharjah: Bentham Science Publishers; 2011.

29. Malafarina V, Uriz-Otano F, Iniesta R, et al. Sarcopenia in the eldelry: diagnosis, physiopathology and treatment. Maturitas 2012; 71(2): 109-114.

30. Bujnowska-Fedak MM, Machaj Z, Steciwko A. Pacjent z zespołem słabości w praktyce lekarza rodzinnego. Terapia 2013; 2(284): 20-27 (in Polish).

31. Kurpas D, Szwamel K, Soll A, et al. Zespół słabości - wytyczne diagnostyki, terapii i prewencji. Terapia 2017; 2: 6-13 (in Polish).

32. Finlayson $M$, Mallinson T, Barbosa VM. Activities of daily living $(A D L)$ and instrumental activities of daily living (IADL) items were stable over time in a longitudinal study on aging. J Clin Epidemiol 2005; 58(4): 338-349.

33. Clegg A, Barber S, Young J, et al. The Home-based Older People's Exercise (HOPE) trial: a pilot randomized controlled trial of a homebased exercise intervention for older people with frailty. Age Aging 2014; 43(5): 687-695.

34. Gitlin LN, Corcoran M, Winter L, et al. A randomized, controlled trial of a home environmental intervention: effect on efficacy and upset in caregivers and on daily function of persons with dementia. Gerontologist 2001; 41(1): 4-14.

35. Toulotte C, Fabre C, Dangremont B, et al. Effects of physical training on the physical capacity of frail, demented patients with a history of falling: a randomized controlled trial. Age Aging 2003; 32(1): 67-73.

36. Peri K, Kerse $\mathrm{N}$, Robinson $\mathrm{E}$, et al. Does functionally based activity make a difference to health status and mobility? A randomized controlled trial in residential care facilities (The Promoting Independent Living Study; PILS). Age Ageing 2008; 37(1): 57-63.

37. Timonen L, Rantanen T, Ryynänen OP, et al. A randomized controlled trial of rehabilitation after hospitalization in frail older women: effects on strength, balance and mobility. Scand J Med Sci Sports 2002; 12(3): 186-192.

38. Gill TM, Baker DI, Gottschalk M, et al. A program to prevent functional decline in physically frail, elderly persons who live at home. N Engl J Med 2002; 347(14): 1068-1074.

39. Chou $\mathrm{CH}$, Hwang $\mathrm{CL}$, Wu YT. Effect of exercise on physical function, daily living activities and quality of life in the frail older adults: a meta-analysis. Arch Phys Med Rehabil 2012; 93(2): 237-244.

40. Cadore EL, Rodríguez-Mañas L, Sinclair A, et al. Effects of different exercise interventions on risk of falls, gait ability, and balance in physically frail older adults: a systematic review. Rejuvenation Res 2013; 16(2): 105-114.

41. Brismee JM, Paige RL, Chyu MC, et al. Group and home-basen tai chi in elderly subjects with knee osteoarthritis: a randomized controlled trial. Clin Rehabil 2007; 21(2): 99-111.

42. Wolf SL, Sattin RW, Kutner M, et al. Intense tai chi exercise training and fall occurrences in older, transitionally frail adults: a randomized, controlled trial. J Am Geriatr Soc 2003; 51(12): 1693-1701.

43. Cadore E, Casas-Herrero A, Zambom-Ferraresi F, et al. Multicomponent exercises including muscle power training enhance muscle mass, power output, and functional outcomes in institutionalized frail nonagenarians. Age (Dordrecht) 2014; 36(2): 773-785.

44. Sato D, Kaneda K, Wakabayashi H, et al. The water exercise improves health-related quality of life of frail elderly people at day service facility. Qual Life Res 2007; 16(10): 1577-1585.

45. Hauer K, Pfistere M, Schuler M, et al. Two years later: a prospective long-term follow-up of a training intervention in geriatric patients with a history of severe falls. Arch Phys Med Rehabil 2003; 84(10): 1426-1432.

46. Chan DCD, Tsou HH, Chang CB, et al. Integrated care for geriatric frailty and sarcopenia: a randomized control trial. J Cachexia Sarcopenia Muscle 2017; 8(1): 78-88.

47. Wolf SL, Barnhart HX, Kutner NG, et al. Reducing frailty and falls in older persons: an investigation of Tai Chi and computerized balance training. Atlanta FICSIT Group. Frailty and Injuries: Cooperative Studies of Intervention Techniques. J Am Geriatr Soc 1996; 44(5): 489-497.

48. Artaza-Artabe I, Sáez-López P, Sánchez-Hernández N, et al. The relationship between nutrition and frailty: effects of protein intake, nutritional supplementation, vitamin D and exercise on muscle metabolism in the elderly. A systematic review. Maturitas 2016; 93: 89-99.

49. Płudowski P, Karczmarewicz E, Bayer M, et al. Practical guidelines for the supplementation of vitamin $D$ and the treatment of deficits in Central Europe - recommended vitamin D intakes in the general population and groups at risk of vitamin D deficiency. Endokrynol Pol 2013; 64(4): 319-327.

50. Morley JE, Argiles JM, Evans WJ, et al. Nutritional recommendations for the management of sarcopenia. J Am Med Dir Assoc 2010; 11(6): 391-396.

51. Rejnmark L. Effects of vitamin D on muscle function and performance: a review of evidence from randomized controlled trials. Ther Adv Chronic Dis 2011; 2(1): 25-37.

52. Pfeifer $M$, Begerow $B$, Minne $H$, et al. Effects of a long-term vitamin $D$ and calcium supplementation on falls and parameters of muscle function in community-dwelling older individuals. Osteoporos Int 2009; 20(2): 315-322.

53. Moreira-Pfrimer LD, Pedrosa MA, Teixeira L, et al. Treatment of vitamin D deficiency increases lower limb muscle strength in institutionalized older people independently of regular physical activity: a randomized double-blind controlled trial. Ann Nutr Metab 2009; 54(4): 291-300.

54. Sato Y, Iwamoto J, Kanoko T, et al. Low-dose vitamin D prevents muscular atrophy and reduces falls and hip fractures in women after stroke: a randomized controlled trial. Cerebrovasc Dis 2005; 20(3): 187-192.

55. Kenny AM, Biskup B, Robbins B, et al. Effects of vitamin D supplementation on strength, physical function, and health perception in older, community-dwelling men. J Am Geriatr Soc 2003 51(12): 1762-1767.

56. Bunout $D$, Barrera $G$, Leiva $L$, et al. Effects of vitamin $D$ supplementation and exercise training on physical performance in Chilean vitamin D deficient elderly subjects. Exp Gerontol 2006; 41(8): 746-752.

57. Brunner RL, Cochrane B, Jackson RD, et al. Calcium, vitamin D supplementation, and physical function in the Women's Health Initiative. J Am Dietetic Assoc 2008; 108(9): 1472-1479.

58. Janssen HC, Samson MM, Verhaar HJ. Muscle strength and mobility in vitamin D-insufficient female geriatric patients: a randomized controlled trial on vitamin D and calcium supplementation. Aging Clin Exp Res 2010; 22(1): 78-84.

59. Latham NK, Anderson CS, Lee A, et al. A randomized, controlled trial of quadriceps resistance exercise and vitamin D in frail older people: the Frailty Interventions Trial in Elderly Subjects (FITNESS). J Am Geriatr Soc 2003; 51(3): 291-299. 
60. Lips $\mathrm{P}$, Binkley $\mathrm{N}$, Pfeifer $\mathrm{M}$, et al. Once-weekly dose of $8400 \mathrm{IU}$ vitamin $\mathrm{D}_{3}$ compared with placebo: effects on neuromuscular function and tolerability in older adults with vitamin D insufficiency. Am J Clin Nutr 2010; 91(4): 985-991.

61. Witham MD, Crighton LJ, Gillespie ND, et al. The effects of vitamin D supplementation on physical function and quality of life in older patients with heart failure: a randomized controlled trial. Circ Heart Fail 2010; 3(2): 195-201.

62. Dhesi JK, Jackson SH, Bearne LM, et al. Vitamin D supplementation improves neuromuscular function in older people who fall. Age Ageing 2004; 33(6): 589-595.

63. Ferrando AA, Sheffield-Moore M, Yevkler CW, et al. Testosterone administration to older men improves muscle function: molecular and physiological mechanisms. Am J Physiol Endocrinol Metab 2002; 282(3): E601-E607.

64. Espinoza S, Walston JD. Frailty in older adults: insights and interventions. Cleve Clin J Med 2005; 72(12): 1105-1112.

65. Muller M, van den Beld AW, van der Shouw YT, et al. Effects of dehydroepiandrosterone and atamestane supplementation on frailty in elderly men. J Clin Endocrinol Metab 2006; 91(10): 3988-3991.

66. Morales AJ, Haubrich RH, Hwang JY, et al. The effect of six months treatment with a $100 \mathrm{mg}$ daily dose of dehydroepiandrosterone (DHEA) on circulating sex steroids, body composition and muscle strength in age-advanced men and women. Clin Endocrinol (Oxford) 1998; 49(4): 421-432.

67. Rudman D, Feller AG, Nagraj HS, et al. Effects of human growth hormone in men over 60 years old. N Engl J Med 1990; 323(1): 1-6.

68. Blackman MR, Sorkin JD, Munzer T, et al. Growth hormone and sex steroid administration in healthy aged women and men: a randomized controlled trial. JAMA 2002; 288(18): 2282-2292.

69. Liu H, Bravata D, Olkin I, et al. Systematic review: the safety and efficacy of growth hormone in the healthy elderly. Ann Intern Med 2007; 146(2): 104-115.

70. Onder G, Penninx BW, Balkrishna R, et al. Relation between use of angiotensin-converting enzyme inhibitors and muscle strength and physical function in older women: an observational study. Lancet 2002; 359(9310): 926-930.

71. Sumukadas $D$, Witham $M$, Struthers $A D$, et al. Effect of perindopril on physical function in elderly people with functional impairment: a randomized controlled trial. CMAJ 2007; 177(8): 867-874.

72. Kelaiditi E, Guyonnet S, Cesari M. Is nutrition important to postpone frailty? Curr Opin Clin Nutr Metab Care 2015; 18(1): 37-42.

73. Volkert D, Berner YN, Berry E, et al. ESPEN guidelines on enteral nutrition: geriatrics. Clin Nutr 2006; 25(2): 330-360.

74. Kim H, Suzuki T, Kim M, et al. Effects of exercise and milk fat globule membrane (MFGM) supplementation on body composition, physical function, and hematological parameters i community-dwelling frail Japanese women: a randomized double blind, placebocontrolled, follow-up trial. PloS One 2015; 10(2): 1-20.

75. Kim CO, Lee KR. Preventive effect of protein-energy supplementation on the functional decline on frail older adults with low socioeconomic status: a community-based randomized controlled study. J Gerontol A Biol Sci Med Sci 2013; 68(3): 309-316.

76. Ng TP, Feng L, Nyunt MS, et al. Nutritional, physical, cognitive, and combination interventions and frailty reversal among older adults: a randomized controlled trial. Am J Med 2015; 128(11): 1225-1236.

77. Report of a Joint FAO/WHO/UNU Expert Consultation held in Geneva, 9-16 April 2002. Protein and amino acid requirements in human nutrition. Geneva: World Health Organization; 2007 [cited 28.06.2017]. Available from URL: http://apps.who.int/iris/bitstream/10665/43411/1/WHO_TRS_935_eng.pdf?ua=1.

78. Paddon-Jones D, Rasmussen BB. Dietary protein recommendations and the prevention of sarcopenia. Curr Opin Clin Nutr Metab Care 2009; 12(1): 86-90.

79. Bischoff-Ferrari HA, Dawson-Hughes B, Staehelin HB, et al. Fall prevention with supplemental and active forms of vitamin D: a metaanalysis of randomized controlled trials. BMJ 2009; 339: b3692, doi: 10.1136/bmj.b3692.

80. Bauer JM, Verlaan S, Bautmans I, et al. Effects of a vitamin D and leucine-enriched whey protein nutritional supplement on measures of sarcopenia in older adults, the PROVIDE study: a randomized, double-blind, placebo-controlled trial. J Am Med Dir Assoc 2015; 16(9): 740-747.

81. Smoliner C, Norman K, Scheufele R, et al. Effects of food fortification on nutritional and functional status in frail elderly nursing home residents at risk of malnutrition. Nutrition 2008; 24(11-12): 1139-1144.

82. Cornish SM, Chilibeck PD. Alpha-linolenic acid supplementation and resistance training in older adults. Appl Physiol Nutr Metab 2009; 34(1): 49-59.

83. Kim HK, Suzuki T, Saito K, et al. Effects of exercise and amino acid supplementation on body composition and physical function in community-dwelling elderly Japanese sarcopenic women: a randomized controlled trial. J Am Geriatr Soc 2012; 60(1): 16-23.

84. Dillon EL, Sheffield-Moore M, Paddon-Jones D, et al. Amino acid supplementation increases lean body mass, basal muscle protein synthesis, and insulin-like growth factor-I expression in older women. J Clin Endocrinol Metab 2009; 94(5): 1630-1637.

85. Flakoll P, Sharp R, Baier S, et al. Effect of beta-hydroxy-beta-methylbutyrate, arginine, and lysine supplementation on strength, functionality, body composition, and protein metabolism in elderly women. Nutrition 2004; 20(5): 445-451.

86. Vukovich MD, Stubbs NB, Bohlken RM. Body composition in 70-year-old adults responds to dietary beta-hydroxy-beta-methylbutyrate similarly to that of young adults. J Nutr 2001; 131(7): 2049-2052.

87. Deutz NE, Pereira SL, Hays NP, et al. Effect of beta-hydroxy-beta-methylbutyrate (HMB) on lean body mass during 10 days of bed rest in older adults. Clin Nutr 2013; 32(5): 704-712.

88. Stout JR, Smith-Ryan AE, Fukuda DH, et al. Effect of calcium beta-hydroxy-beta-methylbutyrate (CaHMB) with and without resistance training in men and women 65+yrs: a randomized, double-blind pilot trial. Exp Gerontol 2013; 48(11): 1303-1310.

89. Bonnefoy $\mathrm{M}$, Cornu C, Normand S, et al. The effects of exercise and protein-energy supplements on body composition and muscle function in frail elderly individuals: a long-term controlled randomized study. Br J Nutr 2003; 89(5): 731-739.

90. Bunout $D$, Barrera $G$, de la Maza $P$, et al. The impact of nutritional supplementation and resistance training on the health functioning of free-living Chilean elders: results of 18 months of follow-up. J Nutr 2001; 131(9): 2441s-2446s.

91. Tieland M, Dirks ML, van der Zwaluw N, et al. Protein supplementation increases muscle mass gain during prolonged resistance-type exercise training in frail elderly people: a randomized, double-blind, placebo-controlled trial. J Am Med Dir Assoc 2012; 13(8): 713-719.

92. Chalé A, Cloutier GJ, Hau C, et al. Efficacy of whey protein supplementation on resistance exercise-induced changes in lean mass, muscle strength, and physical function in mobility-limited older adults. J Gerontol A Biol Sci Med Sci 2013; 68(6): 682-690.

93. Tieland $\mathrm{M}$, van de Rest $\mathrm{O}$, Dirks ML, et al. Protein supplementation improves physical performance in frail elderly people: a randomized, double-blind, placebo-controlled trial. J Am Med Dir Assoc 2012; 13(8): 720-726.

94. Villareal DT, Chode S, Parimi N, et al. Weight loss, exercise, or both and physical function in obese older adults. N Engl J Med 2011; 364(13): 1218-1229.

95. Fairhall N, Sherrington C, Kurrle S, et al. Economic evaluation of a multifactorial, interdisciplinary intervention versus usual care to reduce frailty in frail older people. J Am Med Dir Assoc 2015; 16(1): 41-48.

96. Luger E, Dorner TE, Haider S, et al. Effects of a home-based and volunteer-administered physical training, nutritional, and social support program on malnutrition and frailty in older persons: a randomized controlled trial. J Am Med Dir Assoc 2016; 17(7): 671.e9-671. e16, doi: 10.1016/j.jamda.2016.04.018. 
97. Kapan A, Luger E, Haider S, et al. Fear of falling reduced by a lay led home-based program in frail community-dwelling older adults: a randomized controlled trial. Arch Gerontol Geriatr 2017; 68: 25-32.

98. Haider S, Luger E, Kapan A, et al. Associations between daily physical activity, handgrip strength, muscle mass, physical performance and quality of life in prefrail and frail community-dwelling older adults. Qual Life Res 2016; 25(12): 3129-3138.

99. Chan DD, Tsou HH, Yang RS, et al. A pilot randomized controlled trial to improve geriatric frailty. BMC Geriatrics 2012; 12: 58, doi: 10.1186/1471-2318-12-58.

100. Dai B, Li J, Cuijpers P. Psychological treatment of depressive symptoms in Chinese elderly inpatients with significant medical comorbidity: a meta-analysis. BMC Psychiatry 2011; 11: 92, doi: 10.1186/1471-244X-11-92.

101. Wetherell JL, Gatz M, Craske MG. Treatment of generalized anxiety disorder in older adults. J Consult Clin Psychol 2003; 71(1): 31-40.

102. Ostir GV, Ottenbacher KJ, Markides KS. Onset of frailty in older adults and the protective role of positive affect. Psychol Aging 2004; 19(3): 402-408.

103. van Koningsbruggen GM, Harris PR, Smits AJ, et al. Self-affirmation before exposure to health communications promotes intentions and health behavior change by increasing anticipated regret. Communication Res 2016; 43(8): 1027-1044.

104. Parry SW, Bamford C, Deary V, et al. Cognitive-behavioural therapy-based intervention to reduce fear of falling in older people: therapy development and randomized controlled trial - the Strategies for Increasing Independence, Confidence and Energy (STRIDE) study. Health Technol Assess 2016; 20(56): 1-206.

105. Doumas M, Rapp MA, Krampe RT. Working memory and postural control: adult age differences in potential for improvement, task priority, and dual tasking. J Gerontol B Psychol Sci Soc Sci 2009; 64(2): 193-201.

106. Verghese J, Mahoney J, Ambrose AF. Effect of cognitive remediation on gait in sedentary seniors. J Gerontol A Biol Sci Med Sci 2010; 65(12): 1338-1343.

107. Li KZ, Roudaia E, Lussier M, et al. Benefits of cognitive dual-task training on balance performance in healthy older adults. J Gerontol A Biol Sci Med Sci 2010; 65(12): 1344-1352.

108. Smith-Ray RL, Hughes SL, Prohaska TR, et al. Impact of cognitive training on balance and gait in older adults. J Gerontol B Psychol Sci Soc Sci 2015; 70(3): 357-366.

109. Gustafsson S, Wilhelmson K, Eklund K, et al. Health-promoting interventions for persons aged 80 and older are successful in the shortterm results from the randomized and three-armed Elderly Persons in the Risk Zone study. J Am Geriatr Soc 2012; 60(3): 447-454.

110. Monteserin E, Brotons C, Moral I, et al. Effectiveness of a geriatric intervention in primary care: a randomized clinical trial. Fam Pract 2010; 27(3): 239-245.

111. van Hout HP, Jansen AP, van Marwijk HW, et al. Prevention of adverse health trajectories in a vulnerable elderly population through nurse home visits: a randomized controlled trial. J Gerontol A Biol Sci Med Sci 2010; 65(7): 734-742.

112. Favela J, Castro LA, Franco-Marina F, et al. Nurse home visits with or without alert buttons versus usual care in the frail elderly: a randomized controlled trial. Clin Interv Aging 2013; 8: 85-95.

113. Bindels J, Cox K, Widdershoven G, et al. Care for community-dwelling frail older people: a practice nurse perspective. J Clin Nurs 2014; 23(15-16): 2313-2322, doi: 10.1111/jocn.12513.

114. van Kempen JA, Robben SH, Zuidema SU, et al. Home visits for frail older people: a qualitative study on the needs and preferences of frail older people and their informal caregivers. Br J Gen Pract 2012; 62(601): e554-e560, doi: 10.3399/bjgp12X653606.

115. Soll A, Szwamel K, Bujnowska-Fedak MM, et al. Frailty syndrome in community care - tips for patients and their caregivers. MSP 2017; 11(1): 31-36.

116. Tazkarji B, Lam R, Lee S, et al. Approach to preventive care in the elderly. Can Fam Physician 2016; 62(9): 717-721.

117. Barber SE, Clegg AP, Young JB. Is there a role for physical activity in preventing cognitive decline in people with mild cognitive impairment? Age Ageing 2012; 41(1): 5-8.

118. Joyner MJ, Green DJ. Exercise protects the cardiovascular system: effects beyond traditional risk factors. J Physiol 2009; 587(Pt 23): 5551-5558.

119. van Pragg H. Exercise and the brain: something to chew on. Trends Neurosci 2009; 32(5): 283-290.

120. Prazeres F, Santiago L. Relationship between health-related quality of life, perceived family support and unmet health needs in adult patients with multimorbidity attendind primary care in Portugal: a multicenter cross-sectional study. Health Qual Life Outcomes 2016; 14(1): 156.

121. Eurofound. Third European Quality of Life Survey-Quality of life in Europe: subjective well-being. Luxembourg: Publications Office of the European Union; 2013.

122. Ross AC, Taylor CL, Yaktine AL, et al., eds. Dietary reference intakes for Calcium and vitamin D. Washington (DC): National Academies Press (US); 2011.

123. Bischoff-Ferrari HA. Optimal serum 25-hydroxyvitamin D levels for multiple health outcomes. Adv Exp Med Biol 2014; 810: $500-525$.

124. Bolland MK, Leung W, Tai V, et al. Calcium intake and risk of fractures. BMJ 2015; 351: h4580, doi: 10.1136/bmj.h4580.

125. Hansen KE, Johnson RE, Chambers KR, et al. Treatment of vitamin D dedificiency in post-menopausal women. A randomized clinical trial. JAMA Intern Med 2015; 175(10): 1612-1621.

126. Cano A, Kurpas D, Bujnowska-Fedak MM, et al. FOCUS: Frailty Management Optimisation through EIPAHA Commitments and Utilisation of Stakeholders' Input - an innovative European Project in elderly care. Fam Med Prim Care Rev 2016; 18(3): 373-376.

127. Gwyther H, Cooke R, Shaw R, et al. Perceptions and experiences of frailty interventions: quantitative and qualitative results from a survey of partners within the European Innovation Partnership on Active and Healthy Ageing (EIP-AHA). Cambridge University Press. Ageing Soc 2017; 1-25, doi: http://doi.org/10.1017/S044686X17000265.

Tables: 0

Figures: 0

References: 127

Received: 31.05.2017

Revised: 27.06.2017

Accepted: 12.07.2017
Address for correspondence:

Maria Magdalena Bujnowska-Fedak, MD, PhD

Katedra i Zakład Medycyny Rodzinnej UM

ul. Syrokomli 1

51-141 Wrocław

Polska

Tel.: +48 71 326-68-76, +48 606 103-050

E-mail: mbujnowska@poczta.onet.pl 